\title{
The Role of Mechanical Bowel Preparation before lleal Urinary Diversion: A Systematic Review and Meta-Analysis
}

\author{
Shi Deng Qiang Dong Jia Wang Peng Zhang \\ Department of Urology, West China Hospital, Sichuan University, Chengdu, China
}

\section{Key Words}

Bowel preparation - Urethral reconstruction · Radical

cystectomy

\begin{abstract}
Background: Although the use of mechanical bowel preparation (MBP) is still widely promoted as the dogma before patients undergo ileal urinary diversion, an increasing number of clinical trials have suggested that there is no benefit. Thus, we performed a meta-analysis to evaluate the efficacy of MBP in ileal urinary diversion surgery. Methods: A literature search was performed in electronic databases, including PubMed, Embase, Science Citation Index Expanded as well as the Cochrane Library and the Cochrane Clinical Trials Registry, from 1966 to January 1, 2013. Clinical trials comparing outcomes of MBP versus no MBP for ileal urinary diversion surgery were included in the meta-analysis. Pooled odds ratios with 95\% confidence intervals were calculated using the fixed- or random-effects models. Results: In total, two randomized controlled trials and five cohort studies were included in this meta-analysis. The primary outcomes, such as bowel leak and bowel obstruction, showed no statistical difference between the two groups. Additionally, the overall mortality rate and death rate related to operation also manifested that MBP does not offer an advantage over the no MBP. Conclusion: This meta-analysis suggests that
\end{abstract}

MBP does not reduce the incidence of perioperative complications in urinary diversion compared with no MBP. However, large randomized controlled clinical trials are needed to confirm this finding.

(c) 2014 S. Karger AG, Basel

\section{Introduction}

Radical cystectomy (RC) and urinary diversion is the standard resection for muscle-infiltrating bladder tumors and recurrent, high-grade, superficial transitional cell carcinomas that are not controlled by other treatments [ 1 , 2 ]. The second procedure in RC for bladder tumors and other serious bladder diseases is complex and associated with high risks and complications. In virtue of advances in surgical technical and perioperative medical care, its safety has improved significantly in many institutions around the world. Nevertheless, the surgical morbidity remains higher than in any other urologic procedure because of a series of serious complications $[3,4]$.

The key point in reconstructive surgeries on bowel segments is bacterial contamination. To reduce the re-

S. Deng and Q. Dong contributed equally to this work and should be considered as the co-first author.

\section{KARGER}

E-Mail karger@karger.com

www.karger.com/uin
C 2014 S. Karger AG, Basel

$0042-1138 / 14 / 0923-0339 \$ 39.50 / 0$
Prof. Peng Zhang

Department of Urology, West China Hospital Sichuan University

37\# Guoxuexiang Street, Chengdu, 610041 (China)

E-Mail zhangpenghuaxi@163.com 
lated incidence, the routine use of mechanical bowel preparation (MBP) prior to intestinal surgery was considered as a standard practice for many years without changes. However, this reasonable practice was called into question by colorectal surgeons. Through related research, they suggested that bowel preparation was dispensable $[5,6]$, and subsequent meta-analyses of randomized trials arrived at the same conclusion $[7,8]$.

For urinary diversion surgery, information regarding the dogma was scant. Recently, a meta-analysis by Yang et al. [9] comparing comprehensive MBP with limited bowel preparation suggested that there was no advantage to justify strict protocols before surgery. However, there were some limitations in their study. First, the sample size of this study was small because some important articles were not included [10-13]. In addition, limited BP was not really free preparation, but requested the patient to receive oral laxatives.

In order to achieve a more comprehensive conclusion, we designed this meta-analysis. The major objective was to pool the outcomes of ileal urinary diversion with or without MBP and to determine whether there is a difference between these measures.

\section{Materials and Methods}

\section{Study Selection}

A comprehensive literature search in Medline (PubMed), Embase, Science Citation Index Expanded as well as the Cochrane Library and the Cochrane Clinical Trials Registry, from 1966 to January 1, 2013, was performed to identify human trials published in the English language literature to compare MBP versus no MBP for ileal urinary diversion surgery.

The medical subject headings (MeSH) terms or equivalent free texts 'bowel preparation', 'urinary diversion' and 'radical cystectomy' were used in the search strategy. The full electronic search strategy for PubMed is provided in the online supplementary table (www.karger.com/doi/10.1159/000354326). Relevant papers were also identified from the bibliographies of papers obtained through the search. Besides, all relevant studies were identified by the experts in urology.

\section{Inclusion and Exclusion Criteria}

Two authors (S.D. and P.Z.) selected the eligible papers independently. For inclusion in this meta-analysis, a study had to fulfil the following criteria: (1) Patients (there were no restrictions concerning race, age, gender and duration of disease) who had bladder tumors or other serious bladder diseases and who underwent RC and urinary diversion were enrolled in the review. (2) The patients in the no MBP group received no oral laxatives or antibiotics preoperatively and were allowed oral intake before surgery; the patients in the MBP group received oral antibiotics and/or bowel preparation preoperatively. Other interventions were the same between the two groups. (3) At least one of the outcomes concerning surgical complications was mentioned. (4) The papers were English language articles published in peer-reviewed journals; the following studies were not considered for meta-analysis: (a) abstracts, letters, editorials, expert opinions, reviews, and case reports; (b) no relevant result measure reported; (c) studies comparing different bowel preparation solutions rather than $\mathrm{MBP}$ versus no preparation; (d) studies comparing different bowel preparation pattern; (e) patients who received Indiana pouch diversion, previous intestinal surgery, previous radiation or chemotherapy, who had advanced liver or kidney disease and metastatic disease, or who received immunosuppression or antibiotic administration within 1 week before surgery.

\section{Data Extraction and Quality Assessment}

The first author (S.D.) extracted the data independently by using a pre-designed data extraction form including data source, eligibility, methods, participant characteristics, interventions and results. The other author (P.Z.) repeated the same procedures. Inconsistencies were resolved by discussion to achieve a final consensus. When this failed, another author (Q.D.) adjudicated. The Cochrane Collaboration Reviewers' Handbook was used to assess the quality of the included randomized controlled trials (RCTs), including generation of randomization sequences, allocation concealment, blinding of outcome assessment, incomplete outcome data, selective reporting and other bias [14].

\section{Outcome Measurements}

Perioperative complications and related inpatient indicators were evaluated. We divided the complications into three classes: (1) infection-associated complications (Clostridium difficile colitis, urinary tract infection or urosepsis, non-urologic sepsis, abdominal abscess, peritonitis); (2) wound complications (wound infection, wound dehiscence, fascial dehiscence); (3) bowel function-associated complications (bowel obstruction, fistula, bowel leak, postoperative emesis). In addition, we examined the overall mortality rate and death rate related to operation. The primary outcomes were bowel leak, bowel obstruction and mortality; the other complications were all secondary outcomes.

\section{Statistical Analysis}

The Review Manager 5 software (The Cochrane Collaboration, Oxford, UK) was used to analyze the data. The $\chi^{2}$ test was used to detect heterogeneity, with a $\mathrm{p}$ value $<0.100$ considered as statistical significance. The $\mathrm{I}^{2}$ statistic was used for assessing the quantity of heterogeneity, and presence of heterogeneity was considered if $\mathrm{I}^{2}$ was $>50 \%$ [15]. At first, a fixed-effects model was applied. According to DerSimonian and Laird [16], if there was evidence of heterogeneity among the included studies, then the random-effects analysis was used. If these models came to the same conclusion, the results for the fixed-effects model were reported. Otherwise, the results of both the fixed-effects and the random-effects models were reported. For this reason, the results of the meta-analysis [odds ratio (OR) and corresponding 95\% confidence interval (CI)] were presented as more conservative estimates compared with an analysis using a fixed-effects model in the absence of clinical heterogeneity [17]. Different definitions of outcome parameters, variability of interventions and perioperative management could account for the causes of heterogeneity. A subsequent sensitivity analysis was also performed to test the reliability of the results if remarkable heterogeneity existed. 
Fig. 1. Flow diagram depicting the study selection process in accordance with the PRISMA guidelines.

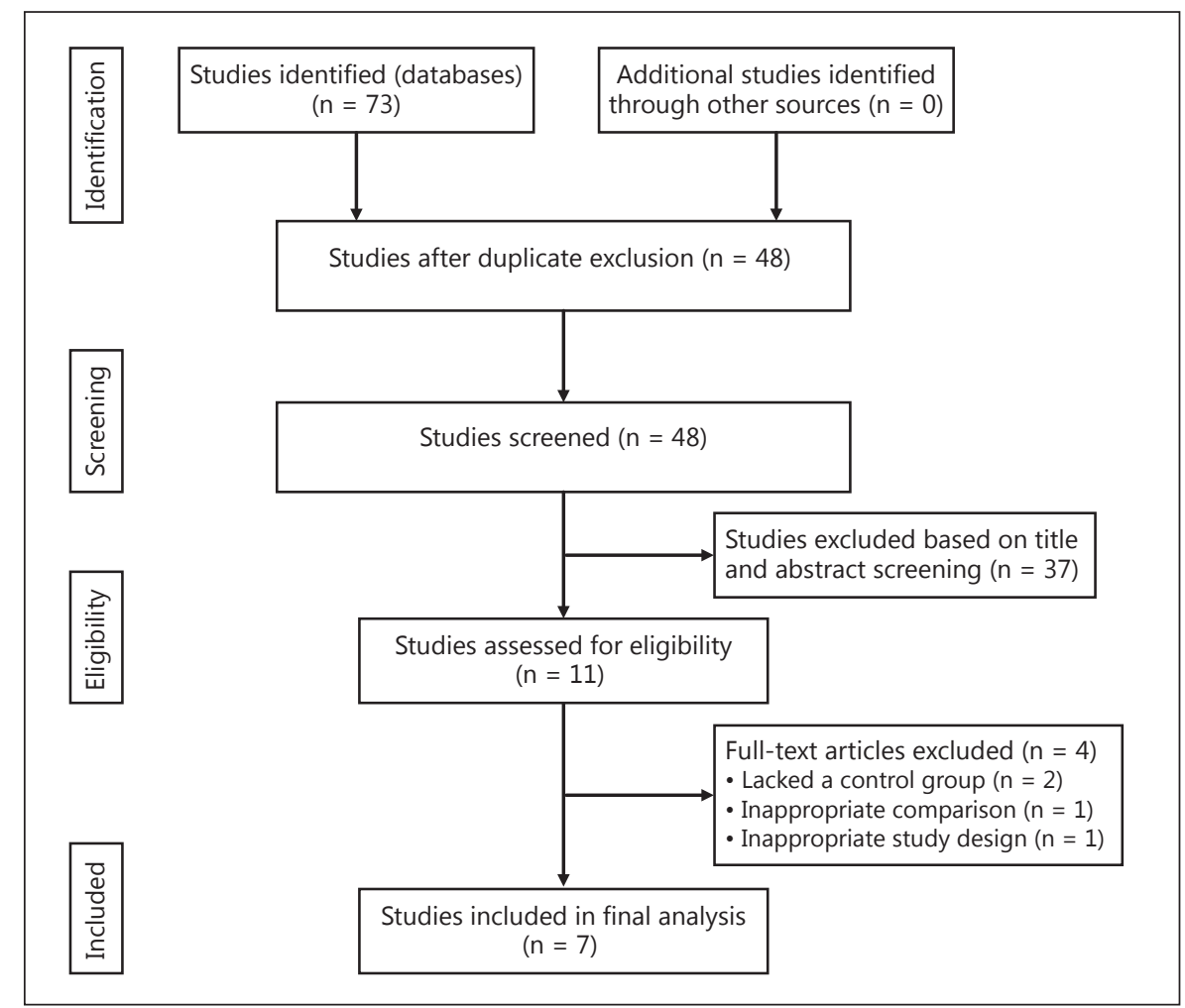

\section{Results}

\section{Trial Characteristics}

Initially, 73 articles were identified. Through initial selection and screening, 62 articles were excluded. The remaining 11 articles were selected for further investigation. Of these, 1 study lacked a control group [18], 2 studies made an inappropriate comparison $[19,20]$, and 1 study focused on old people [21]; these studies were all excluded. In the end, 7 articles were identified for inclusion (two RCTs and five cohort studies) [10-13, 22-24]. The overall risk of bias was unclear in 2 RCTs. Figure 1 shows the selection process using the PRISMA criteria [25]. The study characteristics of the included studies are shown in table 1.

\section{Patient Characteristics}

Most of the patients recruited in the included studies were bladder tumor patients who underwent RC and urinary diversion treatment performed by ileal conduit or orthotopic neobladder. Only 19 cases were neurogenic bladder patients who received ileocystoplasty [22]. Considering that the subjects of this study were the patients who underwent urinary diversion surgery, we did not rule out this research.

Mechanical Bowel Preparation before Urinary Diversion

\section{Meta-Analysis Results}

Infectious Complications. Complications were analyzed by subgroups: Clostridium difficile colitis, urinary tract infection or urosepsis, non-urologic sepsis, peritonitis and abdominal abscess. The test for heterogeneity among studies was not statistically significant, so the fixed-effects model was used for all comparisons. Two studies reported Clostridium difficile colitis and the results did not favor MBP $[10,12]$ (OR 2.97; 95\% CI 0.94$9.33 ; \mathrm{p}=0.06$ ). Five studies described urinary tract infection or urosepsis and the pooled results did not favor MBP (OR 2.97; 95\% CI 0.94-9.33; $p=0.06$ ) [10-12, 23, $24]$. Two studies reported non-urologic sepsis and no difference was found in the incidence with MBP (OR 0.71; 95\% CI 0.10-5.15; $\mathrm{p}=0.73)[11,12]$. Abdominal abscess was described in four studies [10-12, 22]; no difference was found in the incidence with MBP (OR 0.53; 95\% CI $0.15-1.87 ; \mathrm{p}=0.32$ ). Two studies reported peritonitis and no difference was found in the incidence with MBP [11, 22] (OR 2.29; 95\% CI 0.09-58.85; $\mathrm{p}=0.62$ ). The whole subgroup analysis is shown in figure 2 .

Wound Complications. Complications were analyzed by three subgroups: wound infection, wound dehiscence and fascial dehiscence. The test for heterogeneity among 


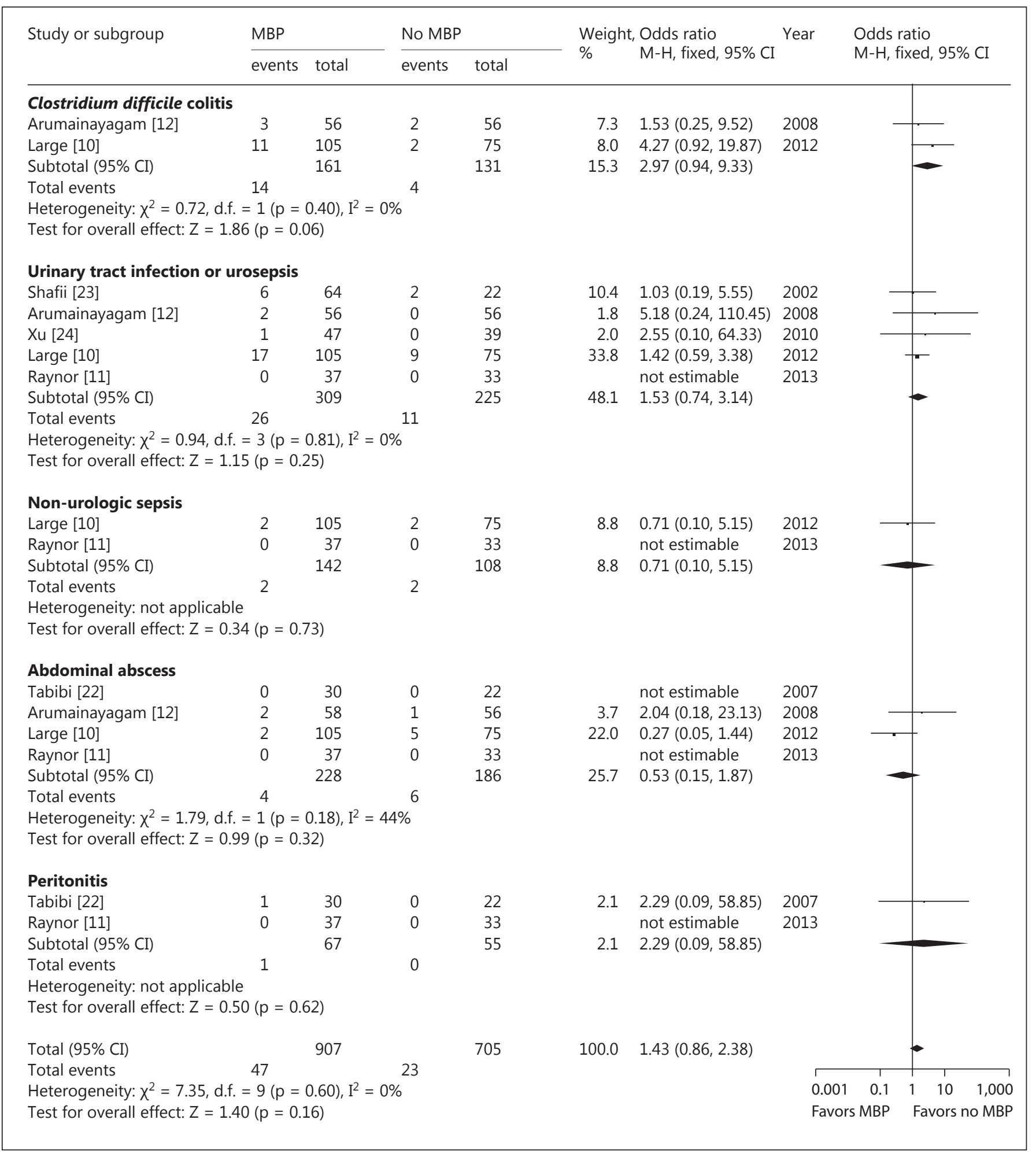

Fig. 2. Meta-analysis of infectious complications. 


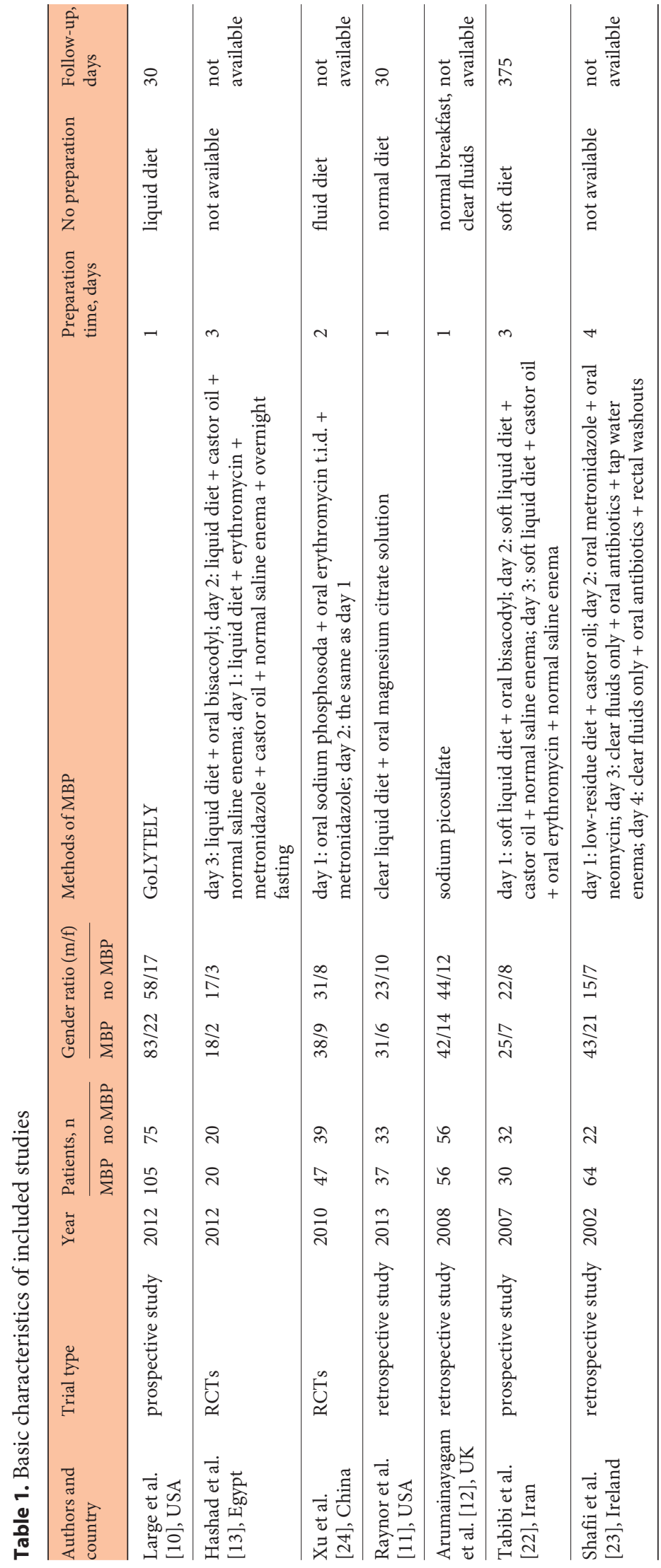

Mechanical Bowel Preparation before Urinary Diversion studies was not statistically significant, so the fixed-effects model was used for all comparisons. All trials reported the rate of wound infection [10-13, 22-24]. The pooled estimate indicated that the outcome measure was not affected by the use of MBP (OR 0.84; 95\% CI 0.41-1.75; $\mathrm{p}=0.65$ ). Wound dehiscence was described in six studies $[10-13,22,23]$; the pooled results failed to support MBP (OR 2.16; 95\% CI 0.92-5.08; $\mathrm{p}=0.08$ ). Two studies reported the number of patients who experienced fascial dehiscence postoperatively $[10,11]$; the pooled estimate indicated that the outcome measure was not affected by the use of MBP (OR 1.02; 95\% CI 0.22-4.65; $\mathrm{p}=0.098$ ). The whole subgroup analysis is shown in figure 3.

Bowel Function-Associated Complications. Complications were analyzed by the following subgroups: fistula, bowel leak, postoperative emesis and mortality rate. The test for heterogeneity among studies was not statistically significant, so the fixed-effects model was used for all comparisons. All trials reported the rate of bowel obstruction $[10-13,22-24]$. The pooled estimate indicated that the outcome measure was not affected by the use of MBP (OR 1.36; 95\% CI 0.60-3.07; $\mathrm{p}=0.46$ ). Fistula was described in five studies $[10-12,22,23]$. The pooled result showed no difference in the incidence with MBP (OR $0.61 ; 95 \%$ CI $0.23-1.61 ; p=0.32$ ). Five studies reported bowel leak and no difference was found in the incidence with MBP [10-12, 22, 24] (OR 1.11; 95\% CI 0.34-3.64; $\mathrm{p}=0.87$ ). Postoperative emesis was described in two studies [11, 12]; the pooled results showed no difference with MBP (OR 1.71; 95\% CI 0.36-8.25; $\mathrm{p}=0.50$ ). The whole subgroup analysis is shown in figure 4.

Mortality Rate. No difference was found in either perioperative deaths (six trials [10-12, 22-24]) (OR 0.64; 95\% CI $0.26-1.59 ; \mathrm{p}=0.34)$ or death related to operation (three trials $[10,23,24])($ OR $0.89 ; 95 \%$ CI $0.18-4.52 ; \mathrm{p}=$ 0.89 ). The whole subgroup analysis is shown in figures 5 and 6.

\section{Sensitivity Analysis}

A further sensitivity analysis was performed according to the publication type of the included studies. The results are presented in table 2 . They were in line with the aforementioned results, indicating a comforting reliability.

\section{Discussion}

In the 1940s, the idea of bowel preparation emerged and was generally accepted by the 1970s [24]. The formation of this concept has much to do with the following 


\begin{tabular}{|c|c|c|c|c|c|c|c|c|}
\hline \multirow[t]{2}{*}{ Study or subgroup } & \multicolumn{2}{|l|}{ MBP } & \multicolumn{2}{|c|}{ No MBP } & \multirow{2}{*}{\multicolumn{2}{|c|}{$\begin{array}{l}\text { Weight, Odds ratio } \\
\% \quad \text { M-H, fixed, } 95 \% \text { CI }\end{array}$}} & \multirow{2}{*}{\multicolumn{2}{|c|}{$\begin{array}{l}\text { Odds ratio } \\
\mathrm{M}-\mathrm{H} \text {, fixed, } 95 \% \mathrm{CI}\end{array}$}} \\
\hline & events & total & events & total & & & & \\
\hline \multicolumn{9}{|l|}{ Wound infection } \\
\hline Arumainayagam, 2008 [12] & 1 & 56 & 1 & 56 & 3.2 & $1.00(0.06,16.39)$ & & \\
\hline Hashad, 2012 [13] & 7 & 20 & 5 & 20 & 10.7 & $1.62(0.41,6.34)$ & & \\
\hline Large, 2012 [10] & 7 & 105 & 6 & 75 & 21.6 & $0.82(0.26,2.55)$ & - & - \\
\hline Raynor, 2013 [11] & 0 & 37 & 0 & 33 & & not estimable & & \\
\hline Shafii, 2002 [23] & 7 & 64 & 3 & 22 & 13.1 & $0.78(0.18,3.31)$ & & - \\
\hline Tabibi, 2007 [22] & 1 & 30 & 2 & 32 & 6.2 & $0.52(0.04,6.02)$ & & \\
\hline$X u, 2010[24]$ & 3 & 47 & 2 & 39 & 6.8 & $1.26(0.20,7.96)$ & & \\
\hline Subtotal (95\% CI) & & 359 & & 277 & 61.6 & $0.98(0.51,1.86)$ & & - \\
\hline Total events & 26 & & 19 & & & & & \\
\hline \multicolumn{9}{|c|}{$\begin{array}{l}\text { Heterogeneity: } \chi^{2}=1.04, \text { d.f. }=5(p=0.96), I^{2}=0 \% \\
\text { Test for overall effect: } Z=0.07(p=0.95)\end{array}$} \\
\hline \multicolumn{9}{|l|}{ Wound dehiscence } \\
\hline Arumainayagam, 2008 [12] & 10 & 56 & 2 & 56 & 5.4 & $5.87(1.22,28.16)$ & & \\
\hline Hashad, 2012 [13] & 1 & 20 & 0 & 20 & 1.5 & $3.15(0.12,82.16)$ & & \\
\hline Large, 2012 [10] & 6 & 105 & 3 & 75 & 10.9 & $1.45(0.35,6.01)$ & & 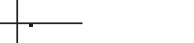 \\
\hline Raynor, 2013 [11] & 0 & 37 & 0 & 33 & & not estimable & & \\
\hline Shafii, 2002 [23] & 3 & 64 & 0 & 22 & 2.3 & $2.56(0.13,51.56)$ & & \\
\hline Tabibi, 2007 [22] & 1 & 30 & 2 & 22 & 7.4 & $0.34(0.03,4.07)$ & & — \\
\hline Subtotal (95\% CI) & & 312 & & 228 & 27.5 & $2.22(0.97,5.06)$ & & - \\
\hline Total events & 21 & & 7 & & & & & \\
\hline \multicolumn{9}{|c|}{ Heterogeneity: $x^{2}=4.06$, d.f. $=4(p=0.40), I^{2}=1 \%$} \\
\hline \multirow{2}{*}{\multicolumn{9}{|c|}{ Fascial dehiscence }} \\
\hline & & & & & & & & \\
\hline Large, 2012 [10] & 3 & 105 & 2 & 75 & 7.5 & $1.07(0.17,6.59)$ & & \\
\hline Raynor, 2013 [11] & 1 & 37 & 1 & 33 & 3.4 & $0.89(0.05,14.80)$ & & \\
\hline Subtotal $(95 \% \mathrm{CI})$ & & 142 & & 108 & 10.9 & $1.02(0.22,4.65)$ & & \\
\hline Total events & 4 & & 3 & & & & & \\
\hline \multicolumn{9}{|c|}{$\begin{array}{l}\text { Heterogeneity: } \chi^{2}=0.01, \text { d.f. }=1(p=0.91), I^{2}=0 \% \\
\text { Test for overall effect: } Z=0.02(p=0.98)\end{array}$} \\
\hline Total $(95 \%$ CI) & & 813 & & 613 & 100.0 & $1.32(0.82,2.13)$ & & - \\
\hline Total events & 51 & & 29 & & & & & \\
\hline \multicolumn{9}{|c|}{ Heterogeneity: $x^{2}=7.09$, d.f. $=12(p=0.85), I^{2}=0 \%$} \\
\hline Test for overall effect: $Z=1$. & $.15(p=$ & $0.25)$ & & & & & $0.01 \quad 0.1$ & $10 \quad 100$ \\
\hline Test for subgroup difference & es: not ap & pplicable & & & & & Favors MBP & Favors no MBP \\
\hline
\end{tabular}

Fig. 3. Meta-analysis of wound complications.

reasons: (1) Bacteria, which were often considered the culprit of relative complications, can be reduced to a maximum [26]. (2) Without the impact by intraluminal hard feces, the anastomotic stoma is relative safer [27]. (3) Time can be saved by skipping the step of clearing feces in the operation, which is safer for the patient [28]. As bowel preparation gained popularity and became widely used in colorectal surgery, pioneers in urology attempted to use this method in urologic surgeries. In 1977, Freiha
[29] described a method of bowel preparation for urologic surgeries. After that, it was widely considered to be classic, almost all urologists followed this practice in RC from then on.

The concept seemed to logical, but was questioned by a series of data obtained by intestinal surgeries. Some clinical trials found no significant benefits obtained from preoperative bowel preparation [30-33], and the related meta-analyses also drew similar disappointed conclu- 


\begin{tabular}{|c|c|c|c|c|c|c|c|c|c|}
\hline \multirow[t]{2}{*}{ Study or subgroup } & \multicolumn{2}{|l|}{ MBP } & \multicolumn{2}{|c|}{ No MBP } & \multirow{2}{*}{$\begin{array}{l}\text { Weight, } \\
\%\end{array}$} & \multirow{2}{*}{$\begin{array}{l}\text { Odds ratio } \\
\mathrm{M}-\mathrm{H} \text {, fixed, } 95 \% \mathrm{CI}\end{array}$} & \multirow[t]{2}{*}{ Year } & \multirow{2}{*}{\multicolumn{2}{|c|}{$\begin{array}{l}\text { Odds ratio } \\
\mathrm{M}-\mathrm{H} \text {, fixed, } 95 \% \mathrm{CI}\end{array}$}} \\
\hline & events & total & events & total & & & & & \\
\hline \multicolumn{10}{|l|}{ Bowel obstruction } \\
\hline Shafii [23] & 12 & 64 & 1 & 22 & 4.2 & $4.85(0.59,39.65)$ & 2002 & & \\
\hline Tabibi [22] & 1 & 30 & 2 & 32 & 6.5 & $0.52(0.04,6.02)$ & 2007 & & \\
\hline Arumainayagam [12] & 0 & 56 & 2 & 56 & 8.6 & $0.19(0.0 .1,4.11)$ & 2008 & & 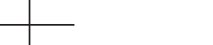 \\
\hline Xu [24] & 1 & 47 & 2 & 39 & 7.4 & $0.40(0.04,4.61)$ & 2010 & & \\
\hline Large [10] & 2 & 105 & 0 & 75 & 2.0 & $3.65(0.17,77.08)$ & 2012 & & \\
\hline Hashad [13] & 2 & 20 & 1 & 20 & 3.1 & $2.11(0.18,25.35)$ & 2012 & & \\
\hline Raynor [11] & 4 & 37 & 2 & 33 & 6.5 & $1.88(0.32,10.99)$ & 2013 & & \\
\hline Subtotal $(95 \% \mathrm{CI})$ & & 359 & & 277 & 38.4 & $1.42(0.65,3.08)$ & & & \\
\hline Total events & 22 & & 10 & & & & & & \\
\hline \multicolumn{10}{|c|}{ Heterogeneity: $\chi^{2}=5.19$, d.f. $=6(p=0.52), I^{2}=0 \%$} \\
\hline \multicolumn{10}{|c|}{ Test for overall effect: $Z=0.88(p=0.38)$} \\
\hline \multicolumn{10}{|l|}{ Fistula } \\
\hline Shafii [23] & 7 & 64 & 2 & 22 & 9.2 & $1.23(0.24,6.41)$ & 2002 & & \\
\hline Tabibi [22] & 1 & 30 & 0 & 32 & 1.6 & $3.31(0.13,84.32)$ & 2007 & & \\
\hline Arumainayagam [12] & 1 & 56 & 3 & 56 & 10.2 & $0.32(0.03,3.19)$ & 2008 & & - \\
\hline Large [10] & 0 & 105 & 3 & 75 & 14.1 & $0.10(0.00,1.93)$ & 2012 & & - \\
\hline Raynor [11] & 0 & 37 & 0 & 33 & & not estimable & 2013 & & \\
\hline Subtotal $(95 \%$ CI) & & 292 & & 218 & 35.1 & $0.61(0.23,1.61)$ & & & \\
\hline Total events & 9 & & 8 & & & & & & \\
\hline \multicolumn{10}{|c|}{ Heterogeneity: $x^{2}=3.49$, d.f. $=3(p=0.32), I^{2}=14 \%$} \\
\hline \multicolumn{10}{|c|}{ Test for overall effect: $Z=1.00(p=0.32)$} \\
\hline \multicolumn{10}{|l|}{ Bowel leak } \\
\hline Tabibi [22] & 1 & 30 & 0 & 32 & 1.6 & $3.31(0.13,84.32)$ & 2007 & & \\
\hline Arumainayagam [12] & 3 & 56 & 2 & 56 & 6.6 & $1.53(0.25,9.52)$ & 2008 & & \\
\hline Xu [24] & 1 & 47 & 1 & 39 & 3.7 & $0.83(0.05,13.65)$ & 2010 & & \\
\hline Large [10] & 0 & 105 & 1 & 75 & 6.0 & $0.24(0.01,5.86)$ & 2012 & & \\
\hline Raynor [11] & 0 & 37 & 0 & 33 & & not estimable & 2013 & & \\
\hline Subtotal $(95 \% \mathrm{CI})$ & & 275 & & 235 & 17.9 & $1.11(0.34,3.64)$ & & & \\
\hline Total events & 5 & & 4 & & & & & & \\
\hline \multicolumn{10}{|c|}{ Heterogeneity: $x^{2}=1.49$, d.f. $=3(p=0.68), I^{2}=0 \%$} \\
\hline \multicolumn{10}{|c|}{ Test for overall effect: $Z=0.17(p=0.87)$} \\
\hline \multicolumn{10}{|l|}{ Postoperative emesis } \\
\hline Arumainayagam [12] & 2 & 56 & 0 & 56 & 1.7 & $5.18(0.24,110.45)$ & 2008 & & \\
\hline Raynor [11] & 2 & 37 & 2 & 33 & 6.9 & $0.89(0.12,6.67)$ & 2013 & & \\
\hline Subtotal $(95 \% \mathrm{CI})$ & & 93 & & 89 & 8.6 & $1.71(0.36,8.25)$ & & & \\
\hline Total events & 4 & & 2 & & & & & & \\
\hline \multicolumn{10}{|c|}{ Heterogeneity: $x^{2}=0.91$, d.f. $=1(p=0.34), I^{2}=0 \%$} \\
\hline \multicolumn{10}{|c|}{ Test for overall effect: $Z=0.67(p=0.50)$} \\
\hline Total $(95 \% \mathrm{CI})$ & & 1,019 & & 819 & 100.0 & $1.10(0.67,1.83)$ & & & - \\
\hline \multirow{2}{*}{\multicolumn{8}{|c|}{ Heterogeneity: $\chi^{2}=12.00$, d.f. $=16(p=0.74), I^{2}=0 \%$}} & 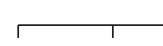 & 1 \\
\hline & & & & & & & & $0.005 \quad 0.1$ & $110 \quad 200$ \\
\hline Test for overall effect: & $8(p=0$. & & & & & & & Favors MBP & Favors no MBP \\
\hline
\end{tabular}

Fig. 4. Meta-analysis of bowel function-associated complications. 


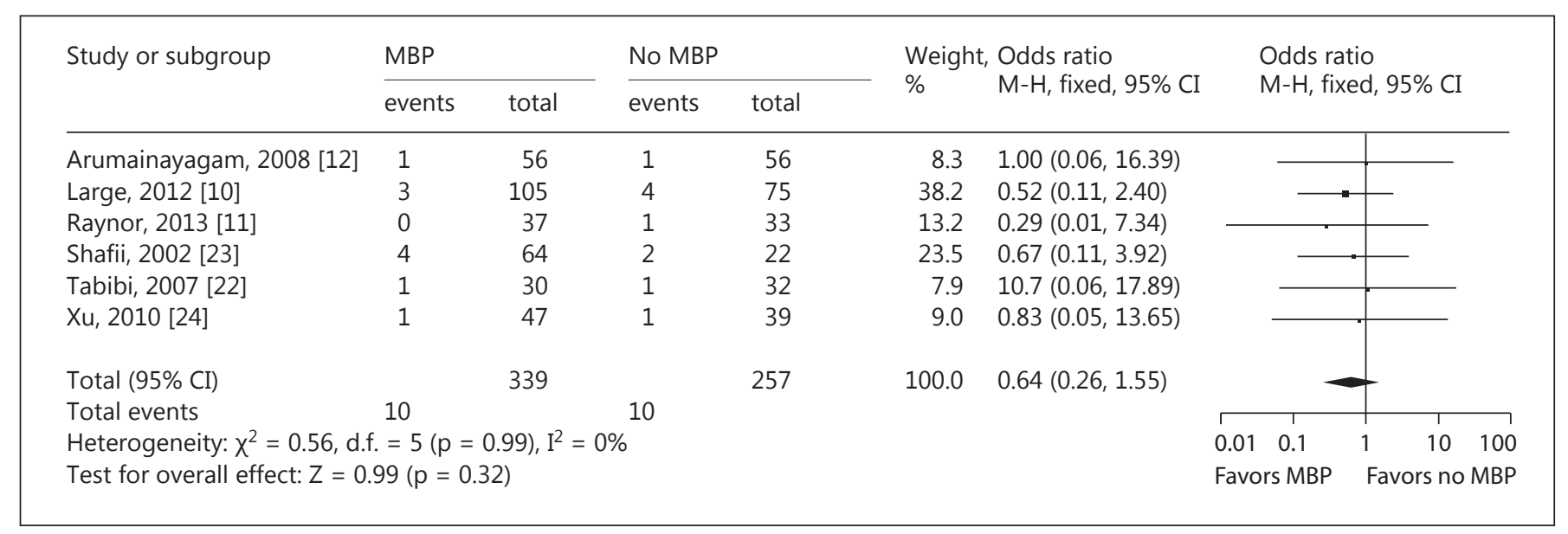

Fig. 5. Meta-analysis of perioperative mortality rate.

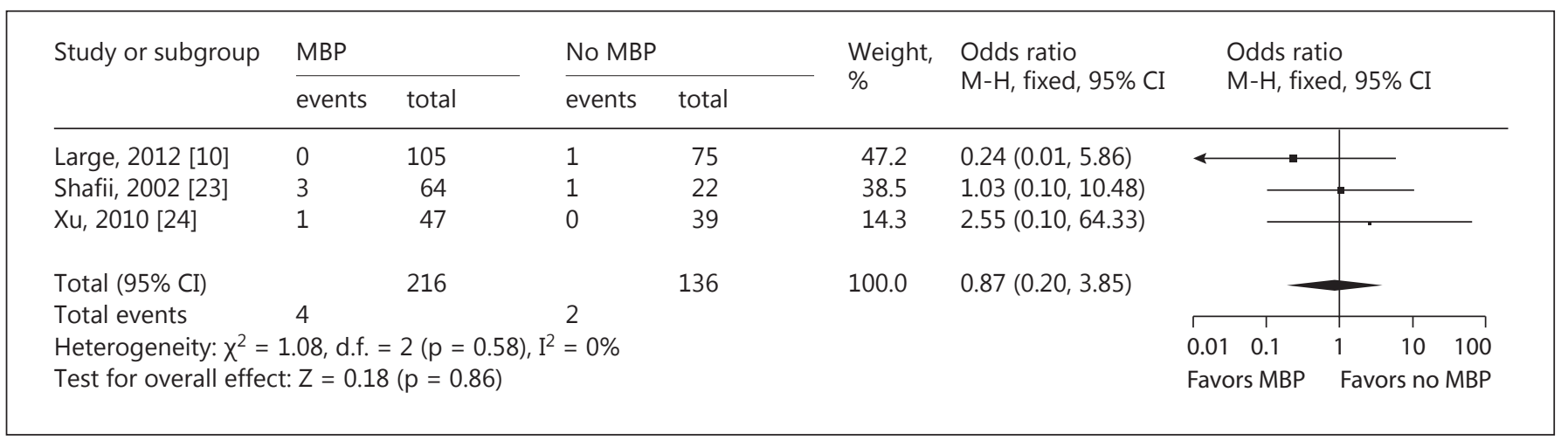

Fig. 6. Meta-analysis of mortality rate related to operation.

sions $[7,8,34]$. In addition, some studies pointed out that this intervention can cause some adverse effects for patients, such as metabolic disturbances and intestinal mucosal architectural change, which both may adversely affect patients' rehabilitation after surgery $[35,36]$.

The emergence of similar reports inspired gastroenterologists and colorectal surgeons to abandon the code. Since there are only a few articles regarding this topic in urologic surgery, the data are limited. Can we abandon this long-standing practice? There is no definitive answer.

Nowadays, there is no clear unified decision-making advice on the efficacy, safety and advantage of that concept for MBP in urology, mostly due to a lack of evidence from large randomized clinical trials. Meanwhile, even when using this method, significant differences were encountered in the application of each method. Just examining the 7 articles included, the type of the enema and the preparation periods were not all the same. Besides, some scholars recognized its inadequacy, but reluctantly abandoned it completely. They thought that limited bowel preparation was equivalent to traditional 3-day bowel preparation [20]. Despite the hundreds of urinary diversion surgeries which are performed in our hospital each year, we are still accustomed to the traditional bowel preparation. We could infer that heterogeneity in the practice patterns would be similar in most countries.

Recently, a meta-analysis by Yang et al. [9] examined comprehensive MBP versus limited bowel preparation and found that there is no advantage to justify strict protocols before surgery. Regrettably, there were some limitations in this study. First, the study sample size was small, just four articles were included. Second, the authors defined limited bowel preparation as no bowel preparation, or at the most a single enema administration before sur- 
Table 2. Sensitivity analysis

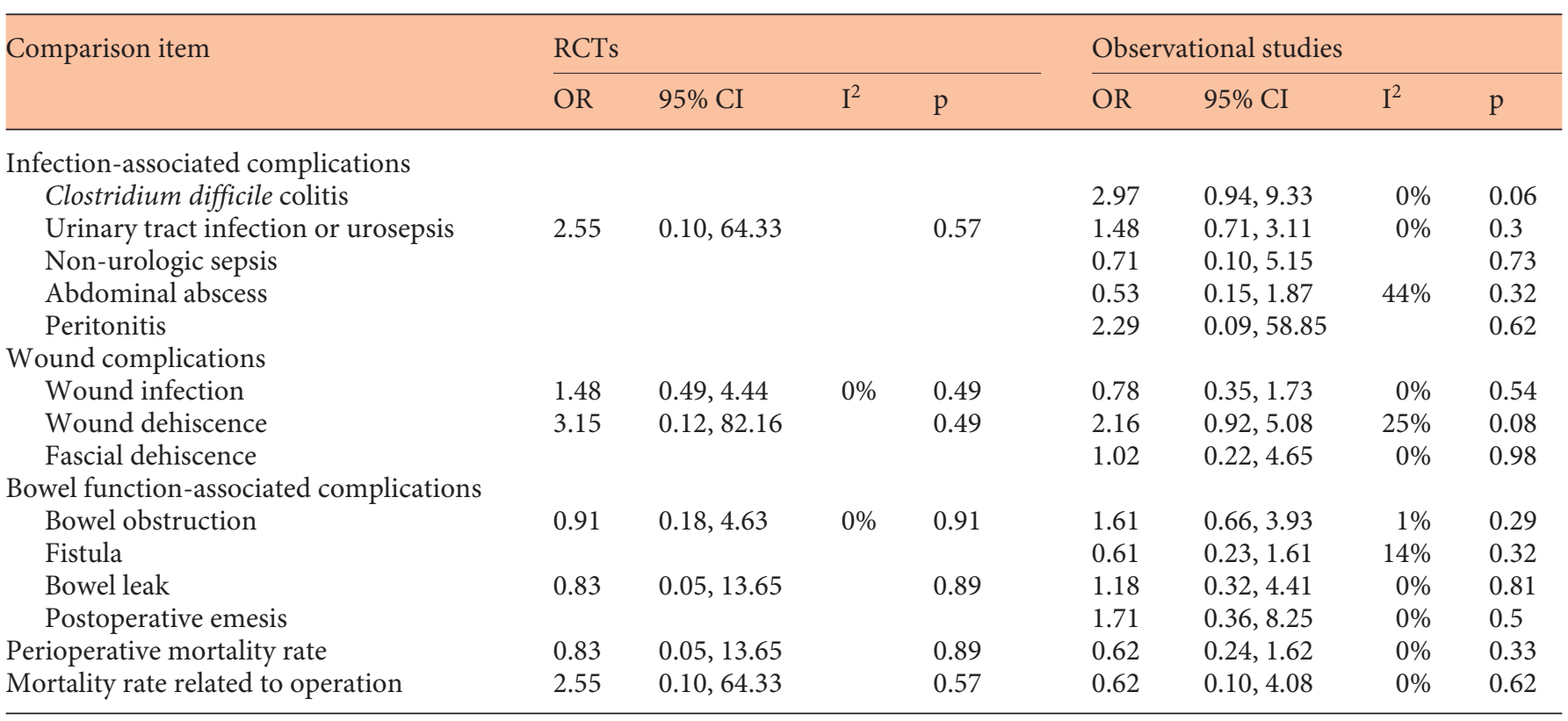

gery. However, limited bowel preparation was not really free preparation; it also requested the patient to receive oral laxatives. Third, by examining the limited bowel preparation pattern in the four articles, we found that three studies used no bowel preparation, just one adopted one-day bowel preparation. Thus, the findings may be not accurate.

For the reasons given above, we designed this analysis to assess the value of preoperative MBP in ileal urinary reconstruction for muscle-invasive bladder cancer and other serious bladder diseases to a certain extent. It included the largest number of patients and showed the synthetically optimal result includes more information and contains all the virtues of multiple evaluation results. As mentioned above, we divided the complications into three classes: infectious complications, wound complications and bowel function-associated complications. None of the statistics confirm that the bowel preparation regimen is beneficial. All research reported the length of hospital stay, and two reports showed a short hospitalization time with bowel preparation $[12,23]$. Due to the different health system models, the index was different. Besides, we failed to merge the data because of different statistical methods for the same reason as the other indexes - day of regular diet, operative time and time to bowel movement. Also, there was no difference in the death rate.

Although we achieved the similar conclusions to those of Yang et al. [9] that MBP did not reduce the incidence of perioperative complications in urinary diversion compared with no preparation, this meta-analysis included more patients, and since the patients in the no MBP group received no oral intestinal lavage solution, the evidence was higher and more novel than that of Yang et al.

Although this review provides the best available evidence for comparison of MBP versus no MBP in urinary diversions to date, as always there are some limitations to this meta-analysis, particularly as a result of the nature of the primary data. To begin with, most of the articles were retrospective studies, and the strength of the evidences was not as powerful as that of RCTs. Second, most of the analyzed studies had different follow-up periods; some even did not report these data. Therefore, potential delayed complications remain uninvestigated, which may lead to an imprecise estimation of any long-term beneficial effects. Third, almost all patients included in this meta-analysis were bladder tumor patients, but this surgical option is not limited to specific populations in urology. Thus, the present findings do not sufficiently apply to urinary diversion surgery.

In conclusion, this meta-analysis suggests that $\mathrm{MBP}$ did not reduce the incidence of perioperative complications in urinary diversion compared with no MBP. Due to limited studies with poor quality, large randomized controlled clinical trials are needed to confirm this finding. 


\section{Acknowledgments}

This work was supported by the National Natural Science Foundation of China (No. 81202023).

\section{Disclosure Statement}

The authors declare no conflict of interest.

\section{References}

1 Peyromaure M, Guerin F, Debre B, Zerbib M: Surgical management of infiltrating bladder cancer in elderly patients. Eur Urol 2004;45: 147-153; discussion 154.

2 Maffezzini M, Audisio R, Pavone-Macaluso M, Hall RR: Bladder cancer. Crit Rev Oncol Hematol 1998;27:151-153.

-3 Novotny V, Hakenberg OW, Wiessner D, Heberling U, Litz RJ, Oehlschlaeger S, Wirth MP: Perioperative complications of radical cystectomy in a contemporary series. Eur Urol 2007;51:397-401; discussion 401-402.

4 Chang SS, Cookson MS, Baumgartner RG, Wells N, Smith JA Jr: Analysis of early complications after radical cystectomy: results of a collaborative care pathway. J Urol 2002;167: 2012-2016.

5 Hughes ES: Asepsis in large-bowel surgery. Ann R Coll Surg Engl 1972;51:347-356.

6 Slim K, Panis Y, Chipponi J: Mechanical colonic preparation for surgery or how surgeons fight the wrong battle (in French). Gastroenterol Clin Biol 2002;26:667-669.

7 Makhija R: Meta-analysis of randomized clinical trials of colorectal surgery with or without mechanical bowel preparation (Br J Surg 2004;91:1125-1130). Br J Surg 2004;91:1528.

8 Slim K, Vicaut E, Launay-Savary MV, Contant C, Chipponi J: Updated systematic review and meta-analysis of randomized clinical trials on the role of mechanical bowel preparation before colorectal surgery. Ann Surg 2009;249:203-209.

-9 Yang L, Chen HS, Welk B, Denstedt JD, Wang K, Li H, Wei Q, Li X: Does using comprehensive preoperative bowel preparation offer any advantage for urinary diversion using ileum? A meta-analysis. Int Urol Nephrol 2013;45: 25-31.

10 Large MC, Kiriluk KJ, DeCastro GJ, Patel AR, Prasad S, Jayram G, Weber SG, Steinberg GD: The impact of mechanical bowel preparation on postoperative complications for patients undergoing cystectomy and urinary diversion. J Urol 2012;188:1801-1805.

11 Raynor MC, Lavien G, Nielsen M, Wallen EM, Pruthi RS: Elimination of preoperative mechanical bowel preparation in patients undergoing cystectomy and urinary diversion. Urol Oncol 2013;31:32-35.

12 Arumainayagam N, McGrath J, Jefferson KP, Gillatt DA: Introduction of an enhanced recovery protocol for radical cystectomy. BJU Int 2008;101:698-701.
13 Hashad MM, Atta M, Elabbady A, Elfiky S, Khattab A, Kotb A: Safety of no bowel preparation before ileal urinary diversion. BJU Int 2012;110:E1109-E1113.

14 Higgins JPT, Green S (eds): Cochrane Handbook for Systematic Reviews of Interventions Version 5.0.2. (updated September 2009). The Cochrane Collaboration 2008. Available from www.cochrane-handbook.org.

15 Higgins JP, Thompson SG, Deeks JJ, Altman DG: Measuring inconsistency in meta-analyses. BMJ 2003;327:557-560.

16 DerSimonian R, Laird N: Meta-analysis in clinical trials. Control Clin Trials 1986;7:177188.

-17 Demets DL: Methods for combining random ized clinical trials: strengths and limitations. Stat Med 1987;6:341-350.

18 Maffezzini M, Campodonico F, Canepa G, Gerbi G, Parodi D: Current perioperative management of radical cystectomy with intestinal urinary reconstruction for muscle-invasive bladder cancer and reduction of the incidence of postoperative ileus. Surg Oncol 2008; 17:41-48.

19 Morey AF, Evans LA, McDonough RC 3rd, Park AM, Sexton WJ, Basler JW, Santucci RA, Amling CL, O'Reilly KJ: Evaluation of mechanical bowel preparation methods in urinary diversion surgery. Can J Urol 2006;13: 3250-3254

20 Aslan G, Baltaci S, Akdogan B, Kuyumcuoğlu U, Kaplan M, Cal C, Adsan O, Turkolmez K, Ugurlu O, Ekici S, Faydaci G, Mammadov E, Turkeri L, Ozen H, Beduk Y: A prospective randomized multicenter study of Turkish Society of Urooncology comparing two different mechanical bowel preparation methods for radical cystectomy. Urol Oncol 2013;31: 664-670.

21 Maffezzini M, Gerbi G, Campodonico F, Parodi D, Capponi G, Spina A, Guerrieri AM: Peri-operative management of ablative and reconstructive surgery for invasive bladder cancer in the elderly. Surg Oncol 2004;13: 197-200.

22 Tabibi A, Simforoosh N, Basiri A, Ezzatnejad M, Abdi H, Farrokhi F: Bowel preparation versus no preparation before ileal urinary diversion. Urology 2007;70:654-658.

23 Shafii M, Murphy DM, Donovan MG, Hickey DP: Is mechanical bowel preparation necessary in patients undergoing cystectomy and urinary diversion? BJU Int 2002;89:879-881.
24 Xu R, Zhao X, Zhong Z, Zhang L: No advantage is gained by preoperative bowel preparation in radical cystectomy and ileal conduit: a randomized controlled trial of 86 patients. Int Urol Nephrol 2010;42:947-950.

25 Liberati A, Altman DG, Tetzlaff J, Mulrow C, Gotzsche PC, Ioannidis JP, Clarke M, Devereaux PJ, Kleijnen J, Moher D: The PRISMA statement for reporting systematic reviews and meta-analyses of studies that evaluate healthcare interventions: explanation and elaboration. BMJ 2009;339:b2700.

26 Jain S, Simms MS, Mellon JK: Management of the gastrointestinal tract at the time of cystectomy. Urol Int 2006;77:1-5.

27 Smith SR, Connolly JC, Gilmore OJ: The effect of faecal loading on colonic anastomotic healing. Br J Surg 1983;70:49-50.

28 Bucher P, Mermillod B, Gervaz P, Morel P: Mechanical bowel preparation for elective colorectal surgery: a meta-analysis. Arch Surg 2004;139:1359-1364; discussion 1365.

29 Freiha FS: Preoperative bowel preparation in urologic surgery. J Urol 1977;118:955-956.

30 Burke P, Mealy K, Gillen P, Joyce W, Traynor $\mathrm{O}$, Hyland J: Requirement for bowel preparation in colorectal surgery. Br J Surg 1994;81: 907-910.

31 Santos JC Jr, Batista J, Sirimarco MT, Guimaraes AS, Levy CE: Prospective randomized trial of mechanical bowel preparation in patients undergoing elective colorectal surgery. Br J Surg 1994;81:1673-1676.

-32 Irving AD, Scrimgeour D: Mechanical bowel preparation for colonic resection and anastomosis. Br J Surg 1987;74:580-581.

33 Bucher P, Gervaz P, Soravia C, Mermillod B, Erne M, Morel P: Randomized clinical trial of mechanical bowel preparation versus no preparation before elective left-sided colorectal surgery. Br J Surg 2005;92:409-414.

34 Guenaga KK, Matos D, Wille-Jorgensen P: Mechanical bowel preparation for elective colorectal surgery. Cochrane Database Syst Rev 2009;1:CD001544.

35 Kim HJ, Yoon YM, Park KN: The changes in electrolytes and acid-base balance after artificially induced acute diarrhea by laxatives. J Korean Med Sci 1994;9:388-393.

-36 Bucher P, Gervaz P, Egger JF, Soravia C, Morel P: Morphologic alterations associated with mechanical bowel preparation before elective colorectal surgery: a randomized trial. Dis Colon Rectum 2006;49:109-112. 